\title{
THE NORMATIVE PLURIVERSE
}

\author{
Matti Eklund
}

$\Lambda^{\mathrm{R}}$

RE THERE NORMATIVE PROPERTIES? Normative realists say yes; various opponents say no. An issue that has been much less discussed is whether there might be a certain kind of multitude of normative properties and what the metaethical consequences are of that kind of normative pluralism.

Here, intuitively, is what is at issue. If all properties are nonnormative, then there are no properties that, so to speak, tell us what to do. If there are normative properties, then some properties tell us what to do. But if there is a multitude of properties telling us what to do, providing different instructions, then we are back at square one.

This paper will be devoted to this kind of normative pluralism and the upshot of taking it seriously. I have just described briefly what this is about. But the aim of the paper is to provide a more careful characterization of the kind of pluralism at issue and of what its significance may be.

Throughout, I will be concerned with relating — and criticizing — what Justin Clarke-Doane has said about these matters. ${ }^{1}$ However, the main aim is constructive: developing the relevant form of normative pluralism and gauging its significance. After having, in section 1, set out the issue, I turn to discuss how exactly we should conceive of the present kind of normative pluralism (in sections 2-5), and then how exactly we should think of the upshot of normative pluralism (sections 6-7). While Clarke-Doane does not much problematize normative pluralism, I think there are serious problems here. And I will argue that while consideration of normative pluralism has serious consequences for how we should think about the normative, it is a delicate matter just how to think of these consequences. More specifically, I will argue that-perhaps appearances to the contrary - the challenge is in effect the same challenge I have already presented in my book Choosing Normative Concepts. The normative pluralism at issue is the same kind of pluralism (although I did not use that label) as that

1 Clarke-Doane, "Objectivity in Ethics and Mathematics," "Objectivity and Evaluation," and Morality and Mathematics. 
which is at issue in my book. And if there is an interesting philosophical upshot (as I believe there is), it is effectively the same as that discussed in my book.

\section{MATHEMATICAL AND NORMATIVE PLURALISM}

There is a certain kind of view in philosophy of mathematics - a kind of pluralism, I will call it, although the pluralist label has been used for many different kinds of views - according to which the mathematical universe is as densely populated as can be. ${ }^{2}$ Roughly, for any logically coherent conception of some mathematical entities, there are entities that satisfy that conception. A careless formulation of the view is that every consistent mathematical theory is true. That cannot be exactly right, for one consistent mathematical theory says that sets satisfy the continuum hypothesis ( $\mathrm{CH}$ ), and another says that they do not, and these two theories cannot both be true. Rather, what the pluralist in question holds is that, for example, there are some set-like entities that make $\mathrm{CH}$ (meaning the version of $\mathrm{CH}$ that concerns them) true and some others that do not make $\mathrm{CH}$ (the version of $\mathrm{CH}$ that concerns them) true. I will ride roughshod over the problems in adequately formulating mathematical pluralism. ${ }^{3}$ I trust that it will be clear enough for present purposes what mathematical pluralism amounts to-and in any case mathematical pluralism will not be my main topic.

In the works mentioned above, Clarke-Doane asks: What about a pluralism in metaethics corresponding to this mathematical pluralism? I will here critically discuss what Clarke-Doane says about the consequences of this kind of normative pluralism, and, more importantly, offer a constructive suggestion regarding the nature and import of a significant kind of normative pluralism.

Clarke-Doane asks us to suppose that all consistent ethical theories "are true," but "of different entities." The mathematical pluralist believes in a mathematical pluriverse; the normative pluralist believes in a normative pluriverse. He then compares the consequences of mathematical pluralism with the consequences of normative pluralism. He thinks that mathematical pluralism in a certain way trivializes mathematics. ${ }^{5}$ Given mathematical pluralism, there are genuine logical questions about what follows from what axioms, and questions about which theory, for example, best captures our concept of set, but no "peculiarly set-the-

2 See, e.g., Balaguer, Platonism and Anti-Platonism in Mathematics; Field, "Which Undecidable Mathematical Sentences Have Determinate Truth-Values?”; and Hamkins, "The Set-Theoretic Multiverse."

3 See sec. 6.2 of Clarke-Doane, Morality and Mathematics, for discussion of such matters.

4 Clarke-Doane, "Objectivity in Ethics and Mathematics," 103.

5 Clarke-Doane, "Objectivity in Ethics and Mathematics," 103. 
oretic questions" are genuine. Turning to normative pluralism, Clarke-Doane asks whether ethics could be "trivialized similarly." $\mathrm{He}$ responds as follows:

Imagine that a philosopher convinces us that, contrary to all appearances, ethics too is like geometry-that every consistent ethical theory is true, albeit true of different entities. In addition to goodness, obligation, and so on, there is shgoodness, shobligation, and so on. Indeed, for every logically consistent ethical theory, there are corresponding properties, and all of them are instantiated "side by side." Knowing that there are logically ... consistent formulations of both deontological and consequentialist ethical theories, we conclude that each is true (albeit of different entities). Is our deliberation as to whether we ought to lie when utility would be maximized thereby trivialized (and likewise for every question on which logically consistent ethical theories diverge)?

It is hard to see how it could be. A general-even if not universalrule is that if we conclude that we ought to $X$, then we cannot continue to regard the view that we ought to not- $X$ as on a par. But given that that view is on a par with respect to truth, learning that "we ought to $X$ " is true seems insufficient to resolve our deliberation. While knowledge that any consistent set theory is true, and knowledge that $\mathrm{zF}+\mathrm{AC}$ and $\mathrm{zF}+\sim \mathrm{AC}$ are both consistent, frees us of the question of whether AC, something similar would not seem to hold in the ethical—and, more generally, normative-case. The fact-value gap appears to be even wider than Hume and Moore suggested. Even knowledge of the normative facts may fail to resolve a normative deliberation. ${ }^{7}$

Clarke-Doane makes two points here. One is that normative questions are not trivialized by normative pluralism in the way that certain mathematical questions are trivialized by mathematical pluralism. The second-which also complicates the first-has to do with the status of normative truths. He says that given normative pluralism, the view that we ought to $X$ and the view that we ought to not- $X$ are on a par with respect to truth, and given this, he thinks, knowledge of the normative truths does not suffice to resolve normative deliberation.

It is tempting to see Clarke-Doane as in effect saying that pluralism presents a challenge for a certain kind of realism, given what he says at the very end of the quoted passage. But one must be careful about what sort of realism is being challenged. Often "realism" is used as a label for all views given that normative propositions are capable of mind-independent truth and falsity, and some atom-

6 Clarke-Doane, "Objectivity in Ethics and Mathematics," 103.

7 Clarke-Doane, "Objectivity in Ethics and Mathematics," 103-4. 
ic normative propositions are true; and that is also how I will use that label here. There is nothing in what Clarke-Doane says that even suggests that he takes normative pluralism to challenge realism in this broad sense. But there is another view that arguably tends to be endorsed by realists: echoing Clarke-Doane's formulation above, this view is that there are some facts knowledge of which properly resolves normative deliberation - facts that settle the normative question of what to do. This view is challenged by Clarke-Doane. The distinction between realism as first characterized and the view challenged by Clarke-Doane can seem elusive, or nonexistent: If there are objectively true normative propositions, are not the facts they state exactly facts that settle normative deliberation? But in my view, one lesson of the issues that come up is that Clarke-Doane is right, and there is reason to draw a distinction here. I will return to this below, in section 7 .

There are other kinds of comparisons that can be made between mathematical pluralism and normative pluralism. It can be held that both sorts of pluralism have the consequence that certain classes of disputes are merely verbal: those who have a dispute "about sets" may simply be using "set" to denote different kinds of entities, and those with a dispute "about what is right" may simply be using "right" for different properties. And it can then further be held that whereas this consequence may be acceptable in the mathematics case, it is unacceptable in the normative case. The main thing I wish to say about the topic of verbal disputes is that this simply is not my topic here. I will focus on the sorts of things Clarke-Doane brings up - in his words, whether there are facts that resolve deliberation. But let me also briefly add that the connection between the pluralism at issue and disputes being merely verbal is by no means straightforward. Even if there are, for example, many different set-like entities, it can still be that disputants nearly always in fact think and talk about the same set-like entities and have real disagreements about them. Whether that is so depends on how it is determined what our thought and talk is about, and that is a vexed issue. ${ }^{8}$

\section{WHAT IS NORMATIVE PLURALISM?}

I agree with Clarke-Doane that attention to a normative pluralism modeled on mathematical pluralism may be of great significance for theorizing about the normative. But I have concerns about how Clarke-Doane conceives of the issue.

8 Balaguer also discusses a normative pluralism modeled on mathematical pluralism in "Moral Folkism and the Deflation of (Lots of) Normative and Metaethics." Much of Balaguer's discussion of this pluralism concerns metasemantic issues. He is not much concerned with the questions about realism and objectivity that Clarke-Doane and I focus on, beyond stressing that the pluralism is consistent with certain forms of realism. 
As I will argue in this and the following sections, it is by no means clear what the normative pluralism at issue in Clarke-Doane's discussion might amount to. In section 5, I will present a constructive suggestion regarding how to understand normative pluralism so that it promises to be of significance. I then turn to the question of the exact nature of the significance of considering normative pluralism. Here too Clarke-Doane will be my foil. I will criticize Clarke-Doane's claims, and present an alternative view on why and how pluralism matters.

Before the substantive discussion, some preliminary remarks. First, I will freely go back and forth between different normative notions when illustrating the issues at hand. Sometimes I will talk about "ought," sometimes about "right." The background assumption is that the issues come up equally in either case, so it does not substantially matter which example we focus on. There is a good question regarding exactly which normative notions we could focus on and still raise essentially the same kind of problem. For example, could one use thick concepts to the same effect? Could one use an example with, say, aesthetically or epistemically normative notions to the same effect? But as a first approximation we can say that the notions in terms of which we raise the problem are the socalled thinnest notions, so those expressed by words like "ought" and "right" in their thinnest, so-called all-things-considered uses.

Second, I will disregard that the words focused on are arguably context-sensitive and express different things as used in different contexts, but will trust it to be clear enough for present purposes what uses of these words I focus on. Third, when speaking about "ought" I will sometimes speak of it as ascribing a property. This is simplified in a couple of ways. For one thing, it strictly ascribes a relation rather than a property. In response to that, I note that "property" is also sometimes used to cover relations. For another, one may hold that "ought" really is an operator. But all I need for present purposes is a simple way to speak of the worldly correlate of "ought." I could in principle speak of what propositions $p$ are such that "Op" expresses a truth, where "O" is an ought-operator, instead of speaking of what has the property ought.

What is the normative pluralism at issue in Clarke-Doane's discussion? Consider Clarke-Doane's talk of being on a par. How should this talk be understood? The view that we ought to $X$ and the view that it is not the case that we ought to $X$ cannot both be true. At most one of these views gets the facts about what we ought to do right. (Compare the set theory case: at most one theory gets the facts about sets right, even if other theories correctly describe other set-like entities. ${ }^{10}$ )

9 Where-following Pickel's usage of the phrase in "Naming, Saying and Structure"-the "worldly correlate" of an expression need not be an entity.

10 Given that there is the plurality of set-like entities postulated by mathematical pluralism, it 
The normative pluralism at issue cannot be that the view that we ought to $X$ and the view that we ought to not- $X$ are both true. Instead it must be something like: there is a property ought, and there is a different but still in some way ought-like property, call it ought $t^{*}$, such that there is the property of being what one ought ${ }^{*}$ to do, and the properties of being what one ought to do and of being what one ought ${ }^{*}$ to do are not coextensive. But once the normative pluralism is more carefully stated-no more flirting with the claim that there are different equally true views regarding what one ought to do-Clarke-Doane's further claims about what normative pluralism yields can seem questionable. Since pluralism is fully compatible with the view that one view is true and the other false, pluralism does not entail that the view that we ought to $X$ and the view that we ought to not- $X$ are on a par. This means that for all that has been said, knowledge of the normative facts can - to use Clarke-Doane's way of putting things - resolve normative deliberation even given normative pluralism as described. Knowledge of what one ought to do can resolve normative deliberation, even if there is also some other property, ought*, such that what one ought to do is not always what one ought to do.

With these initial skeptical remarks as background, consider some more specific concerns along broadly similar lines.

Here is a first point. One dismissive reaction to Clarke-Doane's argument is the following. We simply care more about, and have more reason to care about, what is right, and what ought to be done, than about which mathematical entities are the sets. Given mathematical pluralism, the question "But which are the sets?" remains, and given normative pluralism the question "But what ought I to do?" remains. Insofar as there is a felt difference between the upshots of these kinds of pluralism, the difference is simply that the former question does not seem very important-who cares which ones, of equally real mathematical entities, are the sets? — but the latter question does seem important. ${ }^{11}$ Even if there

is natural to speculate that set talk is referentially indeterminate: our thoughts and practices do not determine precisely which set-like entities we talk about when talking about "sets." This is a complication worth keeping in mind, but it does not conflict with the claim in the main text. A corresponding indeterminacy claim can be made regarding the normative. There are a number of ought-like properties and a number of right-like properties, and our thoughts and practices do not determine precisely which one of these is picked out by our "ought" and by our "right," respectively.

11 Set theory is often appealed to as a foundation for mathematics. There is a question, not in any way trivialized by mathematical pluralism, of which types of mathematical entities are such that a theory of them can serve as a foundation for mathematics. But the pluralist will be apt to hold that different set-like entities are apt to play this role. 
are lots of properties for actions to have, of course it matters what I ought to do! That is all there is to it.

Second, consider the following property, ought+ (or being what one ought+ to do), where an agent ought + to $\phi$ if and only if: she ought to $\phi$ and $\phi$-ing $\neq$ helping someone cross the street on a Thursday. If sometimes helping someone cross the street on a Thursday is what an agent ought to do, ought $+\neq$ ought, but the property ought+ is still ought-like. Ought and ought+ are almost coextensive. But there being this ought-like property in addition to ought itself does not seem to problematize normative deliberation in the least. Normative deliberation concerns what ought to be done, and the possibility of gerrymandered properties like that of what being what one ought+ to do does not immediately do anything to lessen the sense that we are appropriately concerned with what one ought to do. Maybe the properties whose existence is entailed by the normative pluralism that Clarke-Doane describes present no more of a problem than ought+ does. Normative deliberation concerns what ought to be done, and there being in some sense nearby properties does not affect such questions or their significance. (The mathematical pluralism concerned there being mathematical entities corresponding to a variety of mathematical theories, and the notion ought+ was not introduced as corresponding to a normative theory. But this is easily remedied. Just consider a normative theory that in addition to whatever else it says includes a fundamental prohibition on helping someone cross the street on a Thursday.)

Third, a different reason to suspect that there is something off regarding Clarke-Doane's comparison is that, whereas the mathematical pluralism is a controversial hypothesis ("Are there really all these set-like entities?"), one can see the normative pluralism as somewhat trivial. One may reason: of course, say, the property of happiness-maximization that many utilitarians conceive of as rightness ("the utilitarian's property," as I will refer to it) exists, and of course the deontological property of being in accordance with such-and-such maxims ("the deontologist's property") exists, and I can believe in both these properties even if I will identify at most one with rightness. The mathematical pluralism does not seem correspondingly trivial or obvious. Now, the triviality of normative pluralism is not in itself and immediately a problem for Clarke-Doane. It is fully consistent with his discussion of the consequences of normative pluralism that normative pluralism is trivially true, and that mathematical and normative pluralism differ in whether they are trivial. It is rather that there is this difference between mathematical and normative pluralism, and this difference may make us suspect that something has gone awry somewhere. ${ }^{12}$

12 In a number of writings, David Enoch and Tristram McPherson have argued against Scan- 
When considering the seeming triviality of normative pluralism, one must distinguish between two questions. One is whether it is uncontroversial that a given property exists; the other is whether it is uncontroversial that this property can be instantiated. It is possible, after all, that some properties exist despite not being uninstantiated, and even necessarily so. In the case of the utilitarian's and the deontologist's properties, the answers to both questions are affirmative (of course setting aside general skepticism about properties). It may be doubtful whether any actions we actually perform have these properties, but it cannot be in serious doubt that it is possible for there to be actions that have these properties. Moreover, the property ought + is instantiated so long as the property ought is instantiated, and some things we ought to do fail to involve helping someone cross the street on a Thursday.

I have mentioned three ostensibly different concerns with what Clarke-Doane says about normative pluralism. There is what I dubbed the dismissive reaction, the objection from ought + , and the apparent difference in triviality between mathematical pluralism and normative pluralism. These concerns all turn on what exactly normative pluralism comes to. One thing that would deal with these concerns is a formulation of normative pluralism that promises to sidestep these objections. I now turn to the project of finding such a formulation.

\section{NORMATIVITY AND NONNATURALNESS}

Here is a general strategy for finding a formulation of the requisite kind. One can seek to identify a significant property of properties, $X$, and a form of normative pluralism that says that there is a plethora of properties that are $X$. Given the right $X$, this could in principle get around the problems identified. When it comes to the dismissive reaction: if ought, ought ${ }^{*}$, ought ${ }^{* *}$, etc., are all $X$, the continued concern specifically with what ought to be done may start seeming unreasonable, for it may be objected to this continued concern that ought ${ }^{*}$, ought ${ }^{* *}$, etc., are equally $X$. The objection from ought+ is avoided so long as ought+ and other seemingly irrelevant alternatives to ought are not $X$. So long as the $X$-ness of the properties is not trivial, this pluralism is not trivial. Even if the existence of the

lon's broadly quietist view (Scanlon, Being Realistic about Reasons) that Scanlon cannot legitimately claim there to be relevant differences between, e.g., reasons and schmeasons, where schmeasons are a non-coextensive alternative to reasons. See Enoch, Taking Morality Seriously, ch. 5; Enoch and McPherson, “What Do You Mean 'This Isn't the Question'?”; and McPherson, "Against Quietist Normative Realism." Enoch and McPherson undoubtedly raise an important problem for Scanlon. But I doubt that it is a problem for Scanlon's quietism specifically: for the alternative properties and relations threaten to exist on any reasonable metaphysical view. 
properties like the utilitarian's property should be accepted on all hands, their $X$-ness need not be.

This description of the strategy is, to put it mildly, pretty abstract. So let me right away illustrate. One kind of normative pluralism may hold that corresponding to different theories supposed to be about rightness there are (not just different properties but) different normative properties. Here $X=$ normative. Consider how this applies to the problems mentioned. First, the property ought+ perhaps need not be a normative property, even if the property ought is a normative property. Second, if this form of normative pluralism is true, then it becomes more problematic to say that it can still reasonably continue to care specifically about what we ought to do even if there are all these other properties. For if the other properties are normative as well, there may be nothing that distinguishes the property ought as especially worthy of our attention. Third, this would appear to be a less trivial form of normative pluralism. It can be held that it is not that trivial that there is this plethora of normative properties. It is one thing to claim that the utilitarian's property exists, another to claim that it is normative. If the utilitarian's property exists then the conjunctive property of having this property and being normative exists, but it will not be trivial that this conjunctive property can be instantiated.

Another illustration of the strategy might emphasize not the normativity of the properties but the supposed nonnaturalness. Some metaethicists are nonnaturalist realists, holding that normative properties are "nonnatural." Very roughly, this means that they are not part of the aspects of the world that can be studied by the sciences. One could focus on a form of normative pluralism according to which there is a plethora of nonnatural properties. Maybe ought but not ought+ is nonnatural. And if there are all these nonnatural properties, then again-it may be thought - there is nothing that distinguishes the property of being right as especially worthy of our attention. Other properties are metaphysically special in the same way. And it is by no means trivial that there is this plethora of nonnatural properties, or that they can be instantiated.

Both these illustrations of the strategy suggest themselves rather easily. But neither suggestion is in the end workable. Start with the appeal to normativity. Such an appeal invites the question: What is it for a property to be normative? ${ }^{13}$

A first possible answer to this question is that a property is normative if it can be ascribed by a normative predicate. This in turn immediately invites the question of what it is for a predicate to be normative. One cannot very well answer this question in turn by saying that a predicate is normative by virtue of ascribing

13 The discussion in the next few paragraphs is parallel to that in ch. 5 of Eklund, Choosing Normative Concepts. 
a normative property, because of the circularity. And if one holds that a predicate is normative because it can be conventionally used to guide action, a problem is that the normative pluralism again threatens to be rather trivial. Even a die-hard deontologist may agree that a community of utilitarians can use "utilitarian right" to guide action, and that there can be a convention in that community to this effect. ${ }^{14}$ Not only is the normative pluralism trivial: the other, more serious problems also still remain. The property ought+ is still a normative property, so long as some community can use "ought+" to guide action. And given how easy it is for a property to be ascribed by a predicate conventionally used to guide action, the point also remains, for all that has been said: Why should we not continue caring as we have about what ought to be done, even if there are other properties that are normative in the very liberal sense this characterization yields?

A second characterization of what it is for a property to be normative might be that a property is normative by virtue of standing in the right relation-metaphysical necessitation, to a first approximation - to (say) the property of a reason, or the property of what one ought to do. ${ }^{15}$ But this is a nonstarter in the present context. The right-like properties postulated by the would-be normative pluralist will for trivial and irrelevant reasons not be normative in this sense. A right-like property $\neq$ right will not stand in this relation to the property of being a reason, but instead at best to some other reason-like property. But that by itself is insufficient to ward off reasonable concerns that rightness more properly warrants our attention than this right-like property.

A third suggestion regarding the normativity of properties is to say that this is a primitive feature, not amenable to further elucidation. But whatever we say about this primitivism, it does not seem particularly helpful in this context. For what we are after is a feature, $X$, of properties such that $X$ satisfies the desiderata mentioned above. And if normativity is a primitive feature in the sense indicated, we get no handle on whether normativity satisfies these desiderata. Second, while primitivism might sound like a natural way to go, the primitivism at issue would have to be of a special kind. It is a familiar view that a property such as rightness may be primitive. But that is not the relevant kind of view. The relevant kind of view is that, for example, rightness has the primitive feature of normativity. This idea, that normativity is primitive, may again sound familiar. But it should be so taken only if understood as amounting to something like the

I will revisit this kind of reasoning later. Different things can be meant by appeals to "convention."

15 There may be reason to prefer instead appealing to what is part of the nature or essence of the property (see, e.g., Fine, "Essence and Modality"). The points made in the main text still stand. 
view that rightness has the primitive property that it ought to be promoted. But this would just be a version of the previous strategy for explicating normativity. The relevant primitiveness idea is instead that there is a property, normativity, distinct from, and not analyzable in terms of, familiar normative properties like rightness and being what ought to be done. That should seem less familiar, and more like a philosopher's invention.

Fourth, the friend of appeal to normative properties might say something like: to call a property normative is to say that having the property really matters for purposes of normative deliberation. So to say that there are all of these different normative properties involves saying that all of these different properties really matter. But in the present context this is problematic. For example, while informal, the talk of "really mattering" is itself normative, and would naturally be thought to mean something like: is something that ought to be taken into regard. But thus understood, the present suggestion faces a version of a problem already mentioned. It will be trivial that ought but not ought ${ }^{*}$ really matters.

Turn then to the appeal to nonnaturalness. What might "nonnatural" be used to mean here? Common glosses are, like the label "nonnatural" itself, negative: to be nonnatural is to not be discoverable by empirical means, to not be part of the natural world investigated by the sciences. But to the extent that "nonnatural" just means this, I do not see that the property of being nonnatural plausibly could be our $X$. To be sure, the hypothesis that there is a plurality of instantiated nonnatural right-like or ought-like properties is nontrivial. So the third problem is avoided. But I do not see what the significance of such nonnaturalness pluralism could plausibly be for normative deliberation. If in my normative deliberation I tend to focus on questions about what ought to be done and you convince me that there are other nonnatural properties in the negative sense gestured toward, why should that bother me at all? Why can I not set this aside as irrelevant, telling myself that these other nonnatural properties are just different properties? Note, lastly, that the property ought+ is plausibly nonnatural in the negative sense if the property ought is. If the property ought is metaphysically nonnatural then ought+ plausibly is too since the latter is a construct of the former. Moreover, one finds out what one ought+ to do by the same kinds of means as one finds out what one ought to do (except to know whether one ought+ to do something one must also know whether it is an instance of helping someone cross the street on a Thursday).

\section{BECOMING CONVINCED OF NORMATIVE PLURALISM}

My discussion so far has focused on what an interesting form of normative plu- 
ralism analogous to mathematical pluralism might be. Attention to how exactly Clarke-Doane introduces the issue reveals that what he is primarily concerned with is not the truth of some normative pluralist thesis. Rather, he is concerned with the consequences of us becoming convinced that some normative pluralist thesis is true. His reasoning in "Objectivity in Ethics and Mathematics" begins, "Imagine that a philosopher convinces us ..." It may be thought that questions about the exact content of normative pluralism then are not crucial, in the way they would be if the truth of normative pluralism was at issue.

However, the problems regarding the formulation of normative pluralism do not go away, for there remains the question of exactly what it is that we are supposed to be convinced of.

Moreover, so long as the nature of the supposed normative pluralism remains obscure, pluralism seems not to be so central to the challenge. The point, in general terms, appears to be that the truth of a skeptical hypothesis regarding the normative-there are no normative facts knowledge of which is sufficient to resolve deliberation - would not trivialize normative deliberation. The point could equally well be made by appeal to (our having become convinced of the truth of) normative nihilism, the view that there are no normative facts; or, say, radical normative indeterminism, according to which the claims about what we ought to do are always indeterminate in truth-value-it is radically indeterminate what the normative facts are.

One reason not to focus on nihilism specifically might be that nihilism cannot actually be believed. ${ }^{16}$ But even if nihilism cannot be believed, the general point stands: there are views distinct from any form of pluralism whose upshot is the same as the supposed upshot of normative pluralism. Appeal to indeterminism suffices to make the point.

\section{NORMATIVE ROLE}

I believe that the discussion in my Choosing Normative Concepts suggests a workable way of understanding normative pluralism in the context. That discussion is centered on consideration of possible scenarios like the following:

Alternative. There is a linguistic community speaking a language much like English, except for the following differences (and whatever differences are directly entailed). While their words "good," "right," and "ought" are associated with the same normative roles as our words "good," "right," and "ought," their words aren't coextensive with our "good," "right," and 
"ought." So even if they are exactly right about what is "good" and "right" and what "ought" to be done, in their sense, and they seek to promote and to do what is "good" and "right" and what "ought" to be done in their sense, they do not seek to promote what is good and right and what ought to be done. ${ }^{17}$

Here is the philosophical point that I introduce by appeal to such scenarios. Assuming that there is such an alternative, it seems that there is a question to be raised with respect to whether to employ our concepts or their concepts when deciding how to act. At the same time-as I discuss-it is elusive what this supposed "further question" is. Speaking our language and using our "ought" it seems very plausible that one ought to use our concepts; but it seems equally plausible that in their sense of "ought" one ought to use their concepts. But how then can the further question be asked? If we ask the question using normative vocabulary, we must use some particular normative vocabulary or other and then there is the issue of what justifies using that rather than other vocabulary. If instead we ask it using descriptive vocabulary, we seem to have changed the topic in some problematic way. We were interested in what concepts to use when deciding how to act, not in what concepts ascribe properties with such-and-such descriptive features. I will return to the issue of the supposed further question and its non-statability later. ${ }^{18}$

The way I introduce the topic, the notion of normative role becomes of central importance. A concept's normative role is that aspect of its use by virtue of which it figures in practical deliberation in the way it does. The idea behind stating Alternative in terms of alternative concepts sharing normative roles is this. If the others' "ought" figures in normative thinking in the same way as ours does, and the only difference between these expressions concerns aspects of meaning not directly related to normative matters, then there is a clear reason to suspect that the others' "ought" is as much of a claim to be normatively relevant as our "ought."

It may be useful to compare the issue I raise with a well-known argument presented by P. H. Nowell-Smith:

\section{Eklund, Choosing Normative Concepts, 18.}

Given present purposes-getting clear on normative pluralism and its possible upshot-I will not here enter into a more in-depth discussion of the nature of my problem or what may be said in response. For relevant discussion, see Bykvist and Olson, review of Choosing Normative Concepts; Leary, "Choosing Normative Properties”; McDaniel, "Matti Eklund's Choosing Normative Concepts"; McPherson, "Ardent Realism without Referential Normativity"; Plunkett, "Normative Role, Conceptual Variance, and Ardent Realism about Normativity"; and Eklund, "Reply to Bykvist and Olson" and "Reply to Critics." 
Learning about "values" or "duties" might well be as exciting as learning about spiritual nebulae or waterspouts. But what if I am not interested? Why should I do anything about these newly-revealed objects? Some things, I have now learnt, are right and others wrong; but why should I do what is right, and eschew what is wrong? ${ }^{19}$

This purports to be a challenge for familiar forms of realism, according to which facts about values and duties serve to guide action. And intuitively there is something to the challenge. But it is elusive what it is. I may actually fail to be interested in values and duties, as the "what if I am not interested?" alludes to; but what the realist is typically concerned with is rather what I should be interested in. Nowell-Smith asks a rhetorical question about this at the end of the quoted passage. But should this rhetorical question really be accorded any bite? One might say in response that the right things to do trivially are exactly the ones that should be done, because of how our notions of "right" and "should" are related, so the question does not get a grip. It is here that my way of raising the (or a related) issue comes in: even if it is true that I "should do what is right" there are other, nearby truths - I "should* do what is right*" and I am faced with a choice as to which truths to focus on and to let guide my actions. And if one tries to set aside this challenge by just saying that switching focus from what I should do to what I should* do just changes the topic, my response is to stress that if "should" and "should" have the same normative role then there is a clear way in which the should*-facts promise to be as pertinent to action as should-facts are.

The central appeal to normative role suggests an alternative formulation of normative pluralism. The relevant normative pluralist hypothesis is that there are non-coextensive predicates all conventionally associated with the same normative role. (Alternatively put, there are different, non-coextensive properties all ascribed by predicates with the same normative role.) This pluralist hypothesis can threaten to have deflationary consequences of the kind Clarke-Doane is talking about. If $R_{1}$ and $R_{2}$ are two properties picked out by predicates having the normative role associated with "right," one might reasonably wonder what could warrant doing what has $R_{1}$ over doing what has $R_{2}$. Where $\phi$-ing is some type of action, $\phi$-ing may be $R_{1}$ while not- $\phi$-ing is $R_{2}$, but, the thought would be, there is a clear sense in which $\phi$-ing and not $\phi$-ing are on a par. For even if we use "ought" and "right" to, for example, pick out properties under which $\phi$-ing falls, we could have used corresponding normative predicates under which not $\phi$-ing falls; and there is nothing that normatively privileges the properties we actually pick out using normative predicates over the properties we do not so pick out. 
Return now to the three challenges I presented regarding Clarke-Doane's appeal to normative pluralism. Responses to these challenges are now available. Flat-footedly insisting on being concerned with what ought to be done seems dogmatic if other properties are picked out by possible predicates with the same normative role: What favors concern with ought over concern with those other properties? The property ought+ is relevant if, but only if, it is the semantic value of a possible predicate associated with a normative role associated with the concept RIGHT. Just because we can easily define such a property does not mean that it can be the semantic value of such a predicate. And it is not trivial that, for example, the utilitarian's property is picked out by a possible predicate associated with the normative role of our concept RIGHT. So what we have now found is a normative pluralist thesis that promises to be of the right kind for Clarke-Doane's purposes. It avoids the problems discussed earlier.

One potential complication is worth pausing on. It may seem obvious that the utilitarian's property is picked out by some possible predicate associated with the same normative role as that of our concept RIGHT: a community of utilitarians could use a predicate stipulated to stand for the utilitarian's property, and because these people are all convinced that this property is the rightness property that predicate comes to have, for them, the same normative role as our concept RIGHT. The response to this kind of complication is to distinguish between a predicate's being associated with a normative role as a matter of established semantic convention, and its being so associated simply by virtue of what beliefs are prevalent in the community that uses the predicate. It should be specified that it is the first kind of association with normative role that is at issue. ${ }^{20}$

A possible way of rejecting any challenge based on the kind of normative pluralism now at issue may be to say that normative role does determine reference, so that sameness of normative role guarantees sameness of reference.

In my Choosing Normative Concepts, I also consider some scenarios aimed to raise the same questions as Alternative does, but where the different communities' normative concepts do not have the exact same normative roles. ${ }^{21}$ If those scenarios indeed raise the same questions, then the truth of the normative pluralist thesis now at issue is not necessary for the problems concerned to arise. But however that may be, the most urgent matter at hand is that of finding a normative pluralist thesis that promises to be sufficient for the problems to arise.

If the truth of the pluralist thesis now at issue is not in fact necessary for the 
problems to arise, then rejecting this pluralism is of course not sufficient to avoid these problems. ${ }^{22}$

In the next section, I will turn to the question of what exactly the problems raised by normative pluralism are.

\section{CLARKE-DOANE ON THE UPSHOT OF NORMATIVE PLURALISM}

We now have a possible appropriate formulation of normative pluralism, in the sense of a formulation of normative pluralism that promises to be philosophically significant and is not problematic in the way other formulations of pluralism have been. Let us now turn to what might be a significant upshot of (consideration of) this kind of normative pluralism. Let me start by discussing what Clarke-Doane has to say.

As Clarke-Doane states in "Objectivity in Ethics and Mathematics," the supposed upshot of consideration of normative pluralism is that "even knowledge of the normative facts may fail to resolve a normative deliberation." ${ }^{23}$ In more recent work, Clarke-Doane states the upshot in similar ways: "settling the facts, even the normative facts, fails to settle the questions at the center of our normative lives"; "The question of what to do remains after all of our beliefs are all settled."24

Clarke-Doane clearly takes this to be a significant upshot. But might not what is claimed in fact be something trivial? Many philosophers, taking care to distinguish questions about normativity from questions about motivation, would already hold that we can fail to be motivated by knowledge of normative facts: and isn't that a way in which knowledge of normative facts can by itself fail to settle normative deliberation?

Clarke-Doane himself mentions this, and notes that any motivational externalist-holding that the connection between judgment and action is merely contingent-will agree that an agent may fail to be motivated to do that which she has concluded that she ought to do. ${ }^{25}$ He remarks: "The point is that our deliberation as to whether to kill the one is not yet completed even once we conclude that we ought to, that it is the thing to do, that it would be good, that we

22 In "Matti Eklund's Choosing Normative Concepts," Kris McDaniel develops a notion of concepts being conflicting alternatives, and argues that what matters to the challenge I present is not primarily that the alternative concepts at issue have the same normative role but that they are conflicting alternatives in his sense.

23 Clarke-Doane, "Objectivity in Ethics and Mathematics," 104.

24 From Clarke-Doane, "Objectivity and Evaluation," 111, and Morality and Mathematics, 173, respectively.

25 Motivational externalism often concerns moral judgments specifically. Here we are concerned with the thinnest, all-things-considered judgments. 
have reason to, and so on, for any normative properties whatever." ${ }^{26}$ Clarke-Doane thus wants to distinguish his conclusion from that familiar from the debate over externalism. The question is whether he successfully does so. What is it for deliberation to be "completed"? It is natural to hold either that deliberation is completed when a motivation to act has been formed; or that it has been completed when one has arrived at the last conclusion in one's reasoning, if that is different. But if Clarke-Doane says the former, he has not said anything that serves to distinguish his position from that of the externalist. For the externalist will then agree with what the quoted passage says: no conclusion of the kind mentioned serves to complete a normative deliberation. And if Clarke-Doane says the latter, then deliberation may well be completed in the sense at issue even given normative pluralism. Even if there are alternatives to my actual normative concepts, the last conclusion I draw in my reasoning may well simply be one employing one of my own normative concepts. Clarke-Doane needs an alternative notion of the completion of deliberation, and it is hard to see what that alternative might be.

Both in "Objectivity and Evaluation" and in Morality and Mathematics, Clarke-Doane prominently describes the question that has not yet been resolved in terms of Allan Gibbard's notion of what to do. ${ }^{27}$ Conclusions regarding what ought to be done (and what ought* to be done, etc.) do not settle the question of what to do. At least without further guidance with respect to "what to do" one can also reasonably wonder why the pluralist challenge could not extend also to "what to do." Even if $\phi$-ing is what to do, maybe $\psi$-ing is what to $d o^{*}$, where "what to do*" is the counterpart of our "what to do." Raising the pluralist challenge but exempting "what to do" seems unprincipled. Clarke-Doane stresses as important the noncognitivist nature of the "what to do," for example, saying in his Morality and Mathematics that the attitude that resolves deliberation-however exactly to think about it—is not belief. ${ }^{28}$ But how, exactly, is this supposed to help? I only see that it helps if the attitude is or directly entails an actual decision to act, for if that is what the attitude is like then there is no room for thoughts employing alternative concepts to throw a wrench into the decision process. By contrast, if the attitude is anything less than that, then even if I have the attitude that what to do is to $\phi$, I can still equally think that what to $\mathrm{do}^{*}$ is to $\psi$ and that can throw a wrench into my deliberations: that just is the pluralist challenge all over again. Of course, if the relevant feature of the attitude is its decision-likeness then the question of how to distinguish the position from that of the motivational externalist remains: for the motivational externalist too

26 Clarke-Doane, "Objectivity and Evaluation," 111.

27 See Clarke-Doane, "Objectivity and Evaluation," 110, and Morality and Mathematics, 166.

28 Clarke-Doane, Morality and Mathematics, 173. 
distinguishes between conclusions regarding which normative propositions are true and actual decisions regarding how to act.

In Clarke-Doane's more recent work ("Objectivity and Evaluation" and Morality and Mathematics), the supposed upshot of normative pluralism is that realism and objectivity are "in tension." ${ }^{29}$ He thinks there is a clear sense in which mathematical questions, or some of them, are not "objective" given mathematical pluralism. He thinks, for example, that given such pluralism, the question of the truth of the parallel postulate in geometry has no objective answer, since "there are different geometries, each consistent if the others are, and these give different answers to the Parallel Postulate question." ${ }^{30}$ By contrast, practical questions are objective, and their objectivity lies in their very nature. They remain objective even given normative pluralism. Clarke-Doane says,

Practical questions are highly objective in the sense in which austere relativists say they are not. We cannot answer them by disambiguating different notions of ought. Nor can we resolve practical disputes by saying "you take goodmoral and I will take goodmoral*." Only one answer to a practical question is possible, simply because coordinated action requires that we do exactly one thing. ${ }^{31}$

He continues,

And while such questions do not answer to the facts, this is part of the reason why their objectivity is robust. If they did answer to the facts, then their objectivity would be hostage to how plentiful the facts turned out to be. ${ }^{32}$

If realism were true about practical questions, then such questions would answer to the facts, and their objectivity would be hostage to how plentiful the facts are. Since the objectivity of such questions is not thus hostage, realism about practical questions is false.

The notion of objectivity is central in Clarke-Doane's discussion, but he says very little about what he takes objectivity to be. Here is one sort of thing that might be meant by objectivity: a question is objective exactly if it has a mind-independently correct answer. There are, to be sure, good questions about what mind-independent correctness is in the first place. But that is a different story,

The very formulation "in tension" occurs in both works. See, e.g., Clarke-Doane, "Objectivity and Evaluation," 112, and Morality and Mathematics, 174.

Clarke-Doane, "Objectivity and Evaluation," 105.

Clarke-Doane, "Objectivity and Evaluation," 112.

Clarke-Doane, "Objectivity and Evaluation," 112. 
and the issues I will bring up are different from other questions that may be raised about this.

One can readily envisage attempts to problematize the connection between realism and objectivity in this sense. Realism can be argued not to entail objectivity, for realism is compatible with pluralism, and pluralism can be thought to stand in the way of objectivity, in the way Clarke-Doane seeks to illustrate in his discussion of the parallel postulate. (Though see below where I criticize Clarke-Doane's reasoning in this case.) Conversely, objectivity can be argued not to entail realism, so long as "correct" is understood broadly enough that something may be "correct" even if it is not true. For example, one can in principle hold that normative discourse is not fact-stating and normative judgments are not truth-apt, but still think that normative questions have mind-independent correct and incorrect answers-so long as one does not understand correctness to imply truth.

However, even supposing that these points about lack of entailments are correct, that does not mean that the best way to describe the upshot is in terms of there being a tension between such objectivity and realism. That two theses fail to entail each other obviously does not mean that they are in tension.

Now, I very much doubt that Clarke-Doane uses "objective" in the sense of mind-independent correctness. Consider again his reasoning in favor of taking practical questions to be objective. He reaches this conclusion on the basis that only one answer is possible in practical deliberation. There is nothing about how any agent, or any rational agent, must arrive at the same answer. The point is only that in any given instance of an agent being engaged in practical deliberation and the agent arrives at an answer, the agent must arrive at one univocal answer. Call this forced uniqueness: the only kind of answer to a genuinely practical question that one can arrive at is univocal. Now, forced uniqueness is so remote from issues of mind-independent correctness that any argument from forced uniqueness to objectivity in that sense must be seen as a howler. Clarke-Doane cannot really mean mind-independent correctness by "objectivity." This dramatizes the question of what he might mean instead. One possibility is that by "objectivity" he just means forced uniqueness. ${ }^{33}$ It is also forced uniqueness that is suggested by the appeal to Gibbard's notion of "what to do." As noted above, the appeal to a noncognitive attitude concerning "what to do" is immune to a pluralist challenge only if the attitude is decision-like: if it is anything less there is room also to consider what to do*. But if "what to do"-judgments are decision-like then they do not leave room for such further reflection.

The mention of "coordinated action" in the passage quoted above suggests

In Morality and Mathematics, he says, "unique or, as I will say, objective answer" (27). 
that Clarke-Doane has in mind our arriving at the same answer-or at least coordinated answers - to the question of what to do. But this is not a theme that is developed in any way, beyond this one reference to coordinated action.

As mentioned, Clarke-Doane's discussion is centered not on the question of the truth of normative pluralism, but on the question of the consequences of becoming convinced of normative pluralism. He makes the point that certain questions about deliberation seem open even so. That is a point about how normative deliberation appears to us, and about what it is to deliberate. It does not speak to the question of whether there are mind-independently correct ways to deliberate, other than indirectly: it could for example turn out that certain views on deliberation rule out that a question of mind-independent correctness even arises.

Clarke-Doane says that mathematical pluralism rules out that certain mathematical questions have objective answers. One can question this, for reasons rather independent of whatever exactly is meant by "objective." Suppose that mathematical pluralism is true. Then there are many different kinds of geometrical entities for a question like that over the truth of the parallel postulate to be about. Now, either someone asking this question manages to ask a determinate question (the question is about lines ${ }_{1}$, not lines ${ }_{2}$ ), or it is indeterminate whether the question concerns lines or lines $_{2}$. In the first case, there is a unique, and uniquely correct, answer to the question as posed, even given mathematical pluralism. It is hard to see how objectivity is in any way challenged. Turn then to the second case. What we say about that case might depend on the correct account of indeterminacy. But a first point to make is that on plausible understandings of indeterminacy, it is incorrect to say that we have some question that admits of different answers. One view is that there are many different questions, each admitting of unique, and uniquely correct, answers, and it is indeterminate which one is being asked. Another possible view is that while there is a respectable sense in which only one question is being asked, there is a correct answer and it is "indeterminate," or maybe "neither." None of these views on indeterminacy provides support for Clarke-Doane's account. On the first view, pluralism does not stand in the way of each question having an objective answer. On the second view, there is, for all pluralism entails, a unique and uniquely correct answer to the question asked: "indeterminate."

There is a view on indeterminacy that would provide support for Clarke-Doane's claim that with regard to certain mathematical questions, mathematical pluralism rules out that there can be objective answers. This is a view on which only one question is being asked, albeit one that is in some sense indeterminate; and due to the indeterminacy in this question there are several different answers 
that are in some sense correct. Such views are not unheard of. For example, Crispin Wright has defended the view that vagueness gives rise to "permissible disagreement": when a sentence is a borderline sentence due to vagueness one can permissibly judge the sentence to be true and permissibly judge the sentence to be false, even when knowing all the facts about the matter. ${ }^{34}$ Clarke-Doane could use a view like Wright's in order to justify what he says about mathematical pluralism and the parallel postulate.

However, be that as it may, Clarke-Doane explicitly disclaims the suggestion that the reason the parallel postulate question lacks an objective answer has to do with indeterminacy. He allows that the geometrical expressions could be used with determinate meanings on a given occasion of use, and says the question posed using the expressions in this context would still lack an objective answer. ${ }^{35}$ But that just makes it all the more elusive what his talk of objectivity might amount to.

\section{REALISM AND OBJECTIVITY}

In the previous section, I criticized what Clarke-Doane says about the upshot of consideration of normative pluralism for matters related to realism and objectivity. Here I will describe what I take the real upshot to be. Return to the issue of objectivity in the sense of mind-independent correctness. I outlined above how it could be argued from Clarke-Doane's perspective how it could be that the fact that statements within a given discourse are apt for mind-independent correctness does not imply that realism is true of that discourse, and how it could be that the converse does not hold either. The discussion in my Choosing Normative Concepts, briefly rehearsed above, in a different way illustrates how the converse may fail to hold in the case of normative discourse. Even if realism is true of normative discourse it can be that different possible communities can use different normative concepts, and different actions are, so to speak, favored by the different normative concepts used by the different communities. There is then in some sense an issue of which normative concepts to use. But that issue, if it exists, does not seem statable. Either we state it using only nonnormative concepts or we essentially employ some normative concepts. In the former case, we have changed the subject: we are interested in a normative question and not a merely descriptive one. In the latter case, we use some normative concepts or other: but if we use our concepts, we beg the question in favor of them and if we use concepts that are alternatives to ours, we beg the question in favor of those

See Wright, "The Epistemic Conception of Vagueness."

Clarke-Doane, Morality and Mathematics, 27. 
other concepts. It may be that we ought to do what we ought to do; but it may equally be that we ought* to do what we ought* to do. One way to avoid this problem is to deny that the possibility can arise in the first place: to deny that there can be alternatives to our actual concepts, in the sense of concepts having the same normative roles as our concepts but different extensions. The viability of this strategy depends on two things. First, obviously, there is the question of how plausible it is that there can fail to be such alternatives. Second, there is the question of whether this is in the end sufficient. Suppose- to relate to one kind of example I discuss - that we come across a community whose normative concepts are so different from ours that there is no clear sense at all in which specific concepts of theirs are alternatives to specific concepts of ours, and the actions recommended by these concepts are not the same as the actions recommended by our concepts. The possibility of such a community raises the same questions as Alternative. It seems there is an issue of sorts regarding whether to use our concepts or the others' concepts; and as before the supposed issue threatens to be unstatable.

The considerations I present can be seen as an argument for why realism is compatible with the absence of mind-independent correctness. But one must be careful regarding what kind of mind-independent correctness is at issue. The claim is certainly not that there is anything in these considerations that shows that realism is compatible with rejecting the idea that there are mind-independently true claims about what normative propositions are true. Realism was characterized above in terms of mind-independent truth. What the argument shows, if successful, is rather something considerably more elusive: that even if realism is true of normative discourse, there is something - something about deliberation and action-we might have thought had mind-independent correctness conditions but it is unclear what this something might be, even if realism about normative discourse is true and normative sentences express propositions capable of mind-independent truth and falsity. For the structure of the problem I focus on is the following. Suppose realism about normative discourse is true. Normative pluralism can still be true. Given this normative pluralism, Alternative and similar scenarios are possible. A certain demand for mind-independent correctness regarding the normative demands that there be a mind-independently correct answer regarding a supposed further question of which concepts to use. The reason this is properly called a further question is that this supposed question is not immediately answered either by a statement employing our normative expressions nor by a statement employing the others' normative expressions. In my Choosing Normative Concepts, the label ardent re- 
alist is used for the kind of realist who makes a demand for mind-independent correctness of the kind just described.

Whereas for Clarke-Doane it is not the truth of normative pluralism that matters for the pluralist challenge to arise-he considers instead our response to the supposed truth of normative pluralism-for me it is most definitely the truth of normative pluralism that matters. If there are not these alternative normative concepts, then there is not this further question that is crying out to be asked.

The problems in stating the upshot of my considerations are arguably similar to problems we have seen before when discussing Clarke-Doane. He speaks of there not being facts that settle normative deliberation. This is an evocative way of speaking. But, as already brought up, it raises immediate questions. No consideration even promises to show there are no facts such that recognition of them as a matter of fact settles normative deliberation. What is more nearly at issue is whether there are facts such that recognition of them properly settles normative deliberation; or such that recognition of them ought to settle normative deliberation. But these formulations, especially the latter, illustrate a problem regarding stating the upshot: one may think it is fairly trivial that what ought to settle normative deliberation is recognition of facts about what ought to be done. However, another community, using ought* instead, will find it equally trivial that what ought* to settle normative deliberation is recognition of facts about what ought* to be done.

However, even though the problems in stating the upshot are similar, there is a crucial difference. Clarke-Doane positively commits himself to the idea that there is something in normative deliberation - the question of what to do, as he stipulatively calls it-that remains unanswered by factual considerations. By contrast, in the context of my discussion, it is only claimed that there is a certain kind of realist, the ardent realist, who believes there is a further question there (and that this question has a mind-independently correct answer).

Suppose, for argument's sake, that considerations of either my or Clarke-Doane's kind do show that realism about normative discourse is incompatible with the relevant mind-independent correctness thesis (however this latter thesis is to be conceived of, exactly). As we may revert to putting it, for short: suppose that realism rules out mind-independent correctness. This is not yet sufficient for it to be non-misleadingly claimed that there is a tension between realism and mind-independent correctness. For it can be that mind-independent correctness can be ruled out given any view, realist or non-realist. And in fact, the argument against mind-independent correctness seems equally successful whether or not realism is adopted. Suppose you are a non-realist and want to affirm mind-independent correctness. You may think that whole normative discourse is not 
truth-apt; you think normative judgments can be assessed for correctness and some such judgments are mind-independently correct. The pluralist argument can be raised against you too, so long as there are alternative normative concepts to use. Even if the normative judgment that what to do in situation $S$ is to $\phi$ is mind-independently correct, maybe the normative judgment that what to do* in situation $S$ is to $\psi$ is also mind-independently correct.

An immediate concern has to do with whether there can really be this alternative "what to do*." Judgments about what to do are supposed to be special, in that such judgments somehow or other have a more direct connection to action than other judgments do. But first, if the non-realist can reasonably deny that there is such an alternative, the realist can in principle adopt that strategy as well. The realist can say that there is this unique "what to do," while reference-determination functions in such a way that " $\phi$-ing is what to do" has a mind-independent truth-value. Second, once one starts to spell out the details regarding the "what to do," it does seem as if space opens up for possible alternatives. For example, the way Wedgwood describes his ought before action is in terms of what the thinker commits to preferring. But once the psychological notion of preference is employed, one can ask whether there are not relevant alternatives to it. To illustrate this in the most obvious way: "preference" is arguably vague, but then there are alternatives to it corresponding to different ways of precisifying it. The existence of such alternatives to the supposed "what to do" does not show that it is psychologically possible for us to use one of those alternative concepts. But mere psychological impossibility does not mean normative irrelevance. The fact that we psychologically inescapably use some concepts to guide action does not support the normative conclusion that these concepts are somehow normatively privileged over other possible normative concepts.

\section{CONCLUDING REMARKS}

I have had two main aims here: considering how normative pluralism, of the kind at issue, is best construed, and considering what is the upshot of normative pluralism regarding matters of realism and objectivity. In both parts of the discussion, I have used recent work by Clarke-Doane as my target. His work is important since he attempts to carefully lay out pluralism and its implications for realism and objectivity. I have criticized his discussion of what normative pluralism is, and I have separately criticized what he says about the upshot of normative pluralism. Both when it comes to how pluralism is best construed and when it comes to the upshot, I have instead concluded that the challenge presented is best construed as the exact challenge I present in Choosing Normative 
Concepts. Of course, none of this is to provide a straightforward defense of the seriousness of the challenge I present. ${ }^{36}$ While I of course believe the challenge is serious, the claim here is only the restricted one that insofar as pluralism presents a challenge of the kind considered, that challenge is best construed as the challenge that I have elsewhere presented. ${ }^{37}$

Uppsala University matti.eklund@filosofi.uu.se

\section{REFERENCES}

Balaguer, Mark. "Moral Folkism and the Deflation of (Lots of) Normative and Metaethics." In Abstract Objects: For and Against, edited by José L. Falguera and Concha Martínez-Vidal, 297-313. Dordrecht: Springer, 2020.

. Platonism and Anti-Platonism in Mathematics. Oxford: Oxford University Press, 1998.

Bykvist, Krister, and Jonas Olson. Review of Choosing Normative Concepts, by Matti Eklund. Utilitas 31, no. 3 (2019): 343-47.

Clarke-Doane, Justin. Morality and Mathematics. Oxford: Oxford University Press, forthcoming.

. "Objectivity and Evaluation." In Companions in Guilt Arguments in Meta-

ethics, edited by Christopher Cowie and Richard Rowland, 105-17. London:

Routledge, 2019.

- "Objectivity in Ethics and Mathematics." Proceedings of the Aristotelian Society: Virtual Issue 3 (2015): 100-105.

Eklund, Matti. Choosing Normative Concepts. Oxford: Oxford University Press, 2017.

- "Reply to Bykvist and Olson." Utilitas 31, no. 3 (2019): 347-49.

—. "Reply to Critics." Inquiry (forthcoming). Published ahead of print, August 19, 2019. https://doi.org/10.1080/o020174x.2019.1656376.

Enoch, David. Taking Morality Seriously. Oxford: Oxford University Press, 2011. Enoch, David, and Tristram McPherson. "What Do You Mean 'This Isn't the Question'?” Canadian Journal of Philosophy 47, no. 6 (April 2017): 820-40. Field, Hartry. "Which Undecidable Mathematical Sentences Have Determinate

36 See again the discussions referred to in note 18 above.

37 Many thanks to Justin Clarke-Doane, Olle Risberg, and anonymous referees for the Journal of Ethics and Social Philosophy for comments on earlier versions. 
Truth-Values?" In Truth in Mathematics, edited by H. G. Dales and Gianluigi Oliveri, 291-310. Oxford: Oxford University Press, 1998.

Fine, Kit. "Essence and Modality." Philosophical Perspectives 8 (1994): 1-16.

Hamkins, Joel D. “The Set-Theoretic Multiverse." Review of Symbolic Logic 5, no. $3(2012): 416-49$.

Leary, Stephanie. "Choosing Normative Properties: A Reply to Eklund's Choosing Normative Concepts." Inquiry (forthcoming). Published ahead of print, August 18, 2019. https://doi.org/10.1080/0020174X.2019.1656369.

McDaniel, Kris. "Matti Eklund's Choosing Normative Concepts." Inquiry (forthcoming). Published ahead of print, February 7, 2020. https://doi.org/10.1080 /0020174X.2019.1656372.

McPherson, Tristram. "Against Quietist Normative Realism." Philosophical Studies 154, no. 2 (2011): 223-40.

. "Ardent Realism without Referential Normativity." Inquiry (forthcoming). Published ahead of print, September 10, 2019. https://doi.org/10.1080/ 0020174X.2019.1656373.

Nowell-Smith, P.H. Ethics. London: Penguin, 1954.

Pickel, Bryan. "Naming, Saying and Structure." Noûs 51, no. 3 (September 2017): 594-616.

Plunkett, David. "Normative Role, Conceptual Variance, and Ardent Realism about Normativity." Inquiry (forthcoming). Published ahead of print, September 12, 2019. https://doi.org/10.1080/0020174x.2019.1656375.

Scanlon, T.M. Being Realistic about Reasons. Oxford: Oxford University Press, 2014.

Streumer, Bart. "Can We Believe the Error Theory?” Journal of Philosophy 110, no. 4 (April 2013): 194-212.

-. Unbelievable Errors. Oxford: Oxford University Press, 2017.

Wright, Crispin. “The Epistemic Conception of Vagueness." Southern Journal of Philosophy 33, no. S1 (Spring 1995): 133-60. 